\title{
INFLUÊNCIA DE ESTERCO BOVINO E CALCÁRIO SOBRE O EFEITO RESIDUAL DA ADUBAÇÃO FOSFATADA PARA A Brachiaria brizantha CULTIVADA APÓS O FEIJOEIRO(1)
}

\author{
Renato Ferreira de Souza ${ }^{(2)}$, Valdemar Faquin ${ }^{(3)}$, Rodrigo Reis Lima \\ Sobrinho $^{(4)}$ \& Eliezer Augusto Baeta de Oliveira ${ }^{(4)}$
}

\begin{abstract}
RESUMO
A deficiência de $\mathbf{P}$ é uma das limitações mais generalizadas ao estabelecimento e à manutenção de pastagens nas regiões tropicais. Essa deficiência é devida, principalmente, ao baixo teor e aos processos de adsorção/precipitação do $\mathbf{P}$ nos solos. Com o objetivo de avaliar a influência da calagem e da adubação orgânica sobre o efeito residual do $P$, aplicado ao feijoeiro, na nutrição fosfatada e no rendimento do braquiarão cultivado em sucessão, foram conduzidos, em casa de vegetação, quatro experimentos inteiramente ao acaso, em esquema fatorial 4 x 5 e três repetições. Cada unidade experimental foi constituída por um vaso contendo $4 \mathrm{dm}^{3}$ dos solos: Latossolo Vermelho distrófico textura muito argilosa, Latossolo Vermelho-Amarelo distrófico textura argilosa, Latossolo Vermelho-Amarelo distrófico textura média e Neossolo Quartzarênico órtico textura arenosa. Cada solo, representando um experimento, recebeu os tratamentos constituídos de quatro doses de calcário $(0,0 ; 0,5 ; 1,0 ;$ e 2,0 vezes a dose recomendada para elevar a saturação por bases a $60 \%)$ e cinco doses de esterco bovino $(0,0 ; 2,5 ; 5,0 ; 7,5 ;$ e $10,0 \%$ do volume de solo). Os vasos foram cultivados com feijoeiro e, após a colheita deste, cultivaram-se três plantas de braquiarão, as quais foram submetidas a cortes consecutivos aos 70, 160 e 290 dias após a emergência. As produções totais de matéria seca e o acúmulo de $P$ na parte aérea do braquiarão foram positivamente influenciados pela adubação orgânica e pela calagem. Esses tratamentos também influenciaram positivamente o efeito residual da adubação fosfatada, aplicada ao feijoeiro, na nutrição fosfatada e no rendimento do braquiarão.
\end{abstract}

Termos de indexação: adubação orgânica, calagem, disponibilidade de fósforo, pastagem, integração agricultura/pastagem.

\footnotetext{
(1) Projeto financiado pela FAPEMIG e CNPq. Recebido para publicação em junho de 2007 e aprovado em outubro de 2009.

${ }^{(2)}$ DSc. Ciência do Solo e Nutrição de Plantas. Professor Titular UNIPAC/Bom Despacho, Pesquisador EPAMIG/Departamento de Ciência do Solo, Universidade Federal de Lavras - DCS/UFLA. Caixa Postal 37, CEP 37200-000 Lavras (MG). E-mail: souzarf@epamig.br

(3) Professor Titular do Departamento de Ciência do Solo, UFLA. Bolsista CNPq. E-mail: vafaquin@ufla.br

(4) Graduandos em Agronomia, UFLA.
} 


\title{
SUMMARY: INFLUENCE OF CATTLE MANURE AND LIMESTONE ON RESIDUAL EFFECTS OF PHOSPHORUS FERTILIZER IN Brachiaria brizantha GROWN AFTER COMMON BEAN
}

\begin{abstract}
Phosphorus (P) deficiency is one of the most widespread limitations to the establishment and maintenance of pastures in tropical areas. This deficiency is mainly due to the low soil $P$ content and adsorption/precipitation processes. The purpose of this study was to evaluate the influence of manure and lime applications on the residual effect of phosphorus applied to common bean on phosphorus nutrition and yield of Brachiaria brizantha grown in succession. Four experiments were conducted in a greenhouse, in a completely randomized design, in a $4 \times 5$ factorial layout with three replications. Each experimental unit consisted of a pot containing $4 \mathrm{dm}^{3}$ of the following soil: clayey dystrophic Red Latosol (Oxisol), sandy clay loam dystrophic Red-Yellow Latosol (Oxisol), sandy loam dystrophic Red-Yellow Latosol (Oxisol), or sandy orthic Quartzarenic Neosol (Quartzpsament). Each soil represented an experiment and was treated with four liming levels (0.0; 0.5; 1.0 and 2.0 times the recommended dose to reach $60 \%$ base saturation) and five doses of cattle manure (0.0; 2.5; 5.0; 7.5 and $10.0 \%$ of the soil volume). In each pot, bean plants were grown and harvested and followed by planting of three brachiaria plants, which were cut 70, 160 and 290 days after seedling emergency. Total dry matter productions and Paccumulation in the above-ground part of the brachiaria plants were positively influenced by manuring and liming. These treatments influenced positively the residual effect of $P$ fertilizer applied to the bean plants, in terms of $P$ nutrition and production of the succession Brachiaria brizantha crop.
\end{abstract}

Index terms: cattle manure, liming, phosphorus availability, pasture, agriculture/pasture integration.

\section{INTRODUÇÃO}

O Cerrado brasileiro abrange 207 milhões de hectares, dos quais 49,5 milhões são ocupados por pastagens cultivadas (Sano et al., 2000), na sua maioria, pelo gênero Brachiaria; destas, 60 a $70 \%$ apresentam algum nível de degradação e, consequentemente, baixa produtividade (Kluthcouski et al., 2004).

A distribuição geográfica dos fatores limitantes nos solos da América tropical foi feita por Sanches \& Salinas (1981), que concluíram que mais de 70 \% dos solos são intemperizados, pertencentes às ordens dos Latossolos e Argissolos (Embrapa, 1999), e apresentam baixa fertilidade, baixa capacidade de troca catiônica (CTC), acidez elevada, altos teores de Al tóxico, capacidade de retenção de $\mathrm{P}$ alta, cargas variáveis dependentes de $\mathrm{pH}$ associadas, principalmente, à matéria orgânica e predomínio de caulinita e óxidos de Fe e Al na fração argila (Mielniczuk et al., 2003). De acordo com Sanches \& Logan (1992), algumas dessas características manifestam-se mais intensivamente em solos cultivados inadequadamente, ocasionadas pela drástica redução do teor de matéria orgânica do solo (MO), que em solos tropicais intemperizados é responsável pelo aumento da CTC do solo, pela complexação de $\mathrm{Al}$ tóxico e pelo bloqueio dos sítios de adsorção do fosfato.

A deficiência de $\mathrm{P}$ é a limitação nutricional mais generalizada nas pastagens em solos de regiões tropicais, devido à sua precipitação com íons de $\mathrm{Al} \mathrm{e}$ Fe e adsorção aos oxidróxidos de $\mathrm{Fe}$ e $\mathrm{Al}$, abundantes nesses solos (Raij, 1991). Nesses solos altamente intemperizados, predominam os minerais de argila 1:1, como a caulinita e os óxidos de Fe (hematita e goethita) e de $\mathrm{Al}$ (gibbsita) com alta capacidade de adsorção de P. A magnitude desse fenômeno é influenciada pela natureza e quantidade dos sítios de adsorção, que variam em função da mineralogia, da textura, do $\mathrm{pH}$, do balanço de cargas, do teor e qualidade da matéria orgânica, do tipo de ácidos orgânicos e da atividade microbiana do solo (Bahia Filho et al., 1983).

A adoção de sistemas de manejo do solo visando ao aumento do teor de $\mathrm{MO}$, correção do $\mathrm{pH}$ e maior atividade da microbiota do solo pode interferir no processo, reduzindo a adsorção de P. Os grupos funcionais carboxílicos e fenólicos na MO são responsáveis pelo bloqueio dos sítios de adsorção de $\mathrm{P}$ nos óxidos de $\mathrm{Fe}$ e $\mathrm{Al}$, reduzindo sua fixação (Hue, 1991). Também, a elevação do $\mathrm{pH}$ do solo pela calagem, aumentando a concentração e atividade de $\mathrm{OH}^{-}$em solução, promove a precipitação de $\mathrm{Fe}$ e $\mathrm{Al}$, reduzindo a precipitação de $\mathrm{P}-\mathrm{Fe}$ e $\mathrm{P}-\mathrm{Al}$ de baixa solubilidade. Há, ainda, geração de cargas negativas pela desprotonação de hidroxilas expostas nas argilas e na MO, ocorrendo repulsão entre o fosfato e a superfície adsorvente (Mcbride, 1994). Assim, o manejo a que o solo é submetido, alterando os fatores envolvidos na adsorção de $\mathrm{P}$, pode reduzir essa adsorção, aumentando a sua disponibilidade para as 
pastagens. A elevação do $\mathrm{pH}$ dos solos ácidos pela aplicação de calcário apresenta vantagens, como o baixo custo e a fácil aplicação, e representa a principal fonte de $\mathrm{Ca}$ e Mg para as pastagens.

Uma alternativa disponível para a correção da acidez do solo e neutralização de toxidez por $\mathrm{Al}$ é a aplicação de resíduos orgânicos ao solo, que apresenta efeito semelhante ao do calcário (Miyazawa et al., 1993; Franchini et al., 1999; Sumner \& Pavan, 2000). Contudo, devido às dificuldades econômicas e operacionais dessa prática, a rotação lavourapastagem, em sistema integrado de exploração, desponta como boa opção, por proporcionar benefícios recíprocos, eliminando ou reduzindo as causas de degradação resultantes do uso de monocultivo e, ao mesmo tempo, reduzindo os custos da incorporação de MO no agroecossistema (Kluthcouski et al., 2004).

Objetivou-se avaliar a influência de doses de calcário e esterco bovino sobre o efeito residual do $\mathrm{P}$, aplicados previamente na cultura do feijoeiro, na nutrição fosfatada e produção do braquiarão cultivado em sucessão, em quatro solos com diferentes texturas, mineralogias e teores de matéria orgânica.

\section{MATERIAL E MÉTODOS}

Quatro experimentos foram conduzidos no Departamento de Ciência do Solo da Universidade Federal de Lavras, com amostras de quatro solos bem drenados, predominantes no Estado de Minas Gerais, e com ampla variação nos teores de argila, mineralogia e MO, constituindo cada solo um ensaio específico. Para abranger uma ampla variação nas características físicas, químicas e mineralógicas, foram utilizados os solos classificados como: Neossolo Quartzarênico órtico textura arenosa fase Cerrado (RQo), Latossolo Vermelho-Amarelo distrófico textura média fase floresta tropical subperenifólia (LVAd-1), Latossolo Vermelho-Amarelo distrófico textura argilosa fase floresta tropical subperenifólia (LVAd-2) e Latossolo Vermelho distrófico textura muito argilosa fase floresta tropical subperenifólia (LVd) (Embrapa, 1999).

Os solos foram coletados na profundidade de 0 $20 \mathrm{~cm}$, sob vegetação natural, depois da retirada de vegetação e restos orgânicos na superfície. Após a coleta, as amostras foram caracterizadas física, química e mineralogicamente (Quadro 1). A granulometria dos solos foi determinada pelo método da pipeta (Day, 1965), empregando-se $\mathrm{NaOH}$ $0,1 \mathrm{~mol} \mathrm{~L}^{-1}$ como dispersante químico e agitação rápida, sendo a fração areia $(2-0,053 \mathrm{~mm})$ separada por meio de tamisagem. $\mathrm{O} \mathrm{pH}$ em água e os teores de $\mathrm{Ca}^{2+}, \mathrm{Mg}^{2+}, \mathrm{Al}^{3+}, \mathrm{P}, \mathrm{K}^{+}$foram determinados conforme Embrapa (1997), sendo $\mathrm{Ca}^{2+}, \mathrm{Mg}^{2+}$ e $\mathrm{Al}^{3+}$ extraídos com KCl $1 \mathrm{~mol} \mathrm{~L}^{-1}$ e P e K pelo $\mathrm{HCl} 0,05 \mathrm{~mol} \mathrm{~L}^{-1}+$ $\mathrm{H}_{2} \mathrm{SO}_{4} 0,0125 \mathrm{~mol} \mathrm{~L}^{-1}$ (Mehlich-1). Também foram determinados a acidez potencial $(\mathrm{H}+\mathrm{Al})$ e o $\mathrm{C}$ orgânico, conforme Raij et al. (1987). O P remanescente foi determinado conforme Alvarez V. et al. (2000). $\mathrm{Na}$ fração argila, foram quantificadas caulinita $(\mathrm{Ct}) \mathrm{e}$ gibbsita (Gb), mediante Análise Termo Diferencial (ATD). As amostras da mesma fração foram submetidas à difração de raios X, método do pó (Klug $\&$ Alexander, 1974). Os óxidos de Fe livre totais $\left(\mathrm{Fe}_{\mathrm{d}}\right)$ foram extraídos com ditionito-citrato-bicarbonato de sódio (DCB) (Mehra \& Jackson, 1960), e os óxidos de $\mathrm{Fe}$ menos cristalinos $\left(\mathrm{Fe}_{0}\right)$, segundo método de Schwertmann (1964), usando-se oxalato ácido de amônio; em ambos a determinação do Fe foi realizada por espectrofotometria de absorção atômica (Krishna Murti et al., 1966). Os óxidos $\mathrm{SiO}_{2}, \mathrm{Al}_{2} \mathrm{O}_{3}, \mathrm{Fe}_{2} \mathrm{O}_{3}$, $\mathrm{TiO}_{2} \mathrm{eP}_{2} \mathrm{O}_{5}$ foram determinados pelo ataque sulfúrico, segundo Embrapa (1997), sendo calculados os valores de Ki $\left(\mathrm{SiO}_{2} / \mathrm{Al}_{2} \mathrm{O}_{3}\right)$ e $\mathrm{Kr}\left(\mathrm{SiO}_{2} / \mathrm{Al}_{2} \mathrm{O}_{3}+\mathrm{Fe}_{2} \mathrm{O}_{3}\right)$.

Os experimentos foram conduzidos em casa de vegetação, utilizando-se o delineamento experimental inteiramente casualizado, em esquema fatorial $4 \times 5$, inicialmente com quatro repetições, sendo cada unidade experimental constituída por um vaso com capacidade de $4 \mathrm{dm}^{3}$ de solo. Os tratamentos foram constituídos por quatro doses de calcário, equivalentes a $0 ; 0,5 ; 1,0 ;$ e 2,0 vezes as doses recomendadas para elevar a saturação por bases em cada solo a $60 \%$, e por cinco doses de esterco bovino curtido $(0,100,200$, 300 e $400 \mathrm{~cm}^{3}$ ), correspondendo a $0 ; 2,5 ; 5,0 ; 7,5$; e $10 \%$ do volume de solo de cada vaso. Utilizou-se calcário dolomítico calcinado e micropulverizado, com $35 \%$ de $\mathrm{CaO}, 14 \%$ de $\mathrm{MgO}$ e PRNT de $100 \%$. O esterco bovino foi seco a $60{ }^{\circ} \mathrm{C}$ e moído em moinho com malha de $1 \mathrm{~mm}^{2}$, apresentando densidade de 462 $\mathrm{g} \mathrm{dm}^{-3}$. Sua análise química mostrou os seguintes teores de nutrientes: 18,$0 ; 3,4 ; 14,2 ; 12,1 ; 6,0$; e 2,6 $\mathrm{g} \mathrm{kg}^{-1}$ de N, P, K, Ca, Mg e S, respectivamente; 22, 11.012, 449 e $78 \mathrm{mg} \mathrm{kg}^{-1}$ de $\mathrm{Cu}, \mathrm{Fe}, \mathrm{Mn}$ e $\mathrm{Zn}$, respectivamente; e 52,0 \% de MO.

Após 30 dias de incubação, os vasos contendo os solos RQo, LVAd-1, LVAd-2 e LVd receberam aplicação de 200, 250, 320 e $400 \mathrm{mg} \mathrm{dm}^{-3} \mathrm{de} \mathrm{P}$, respectivamente, na forma de $\mathrm{Ca}\left(\mathrm{H}_{2} \mathrm{PO}_{4}\right)_{2} \cdot \mathrm{H}_{2} \mathrm{O}$. Essas doses foram definidas de acordo com as recomendações de Alvarez V. \& Fonseca (1990). Foi também aplicada adubação básica com macro e micronutrientes, constituída de $70 \mathrm{mg}$ de N, $100 \mathrm{mg}$ de K, $40 \mathrm{mg}$ de S, 0,5 mg de B, $1,5 \mathrm{mg}$ de Cu e 5,0 mg dm ${ }^{3}$ de $\mathrm{Zn}$ no solo, utilizandose como fontes reagentes p.a. Depois de 30 dias de incubação, cultivou-se o feijoeiro (Phaseolus vulgaris L., vc. Carioca MG) até a colheita, na época da maturação dos grãos.

Após a colheita do feijoeiro, os solos foram secos, destorroados e peneirados em malha de $5 \mathrm{~mm}$ para a retirada das raízes. Em seguida, os solos das quatro repetições foram misturados bem e retornados aos vasos, nos quais se aplicou adubação básica, constituída de $60 \mathrm{mg} \mathrm{dm}^{-3}$ de solo de $\mathrm{N}, 50 \mathrm{mg}$ de K, $30 \mathrm{mg}$ de $\mathrm{S}, 0,8 \mathrm{mg}$ de B, 1,0 mg de Cu e 2,5 mg de Zn 
Quadro 1. Atributos químicos, físicos e mineralógicos de amostras, coletadas na camada de 0 a $20 \mathrm{~cm}$, de quatro solos sob vegetação nativa

\begin{tabular}{|c|c|c|c|c|c|c|c|c|c|c|c|c|c|c|c|c|}
\hline \multirow{2}{*}{ Solo ${ }^{(1)}$} & \multirow[b]{2}{*}{$\mathrm{pH}^{(2)}$} & \multirow[b]{2}{*}{$\mathbf{P}$} & \multirow[b]{2}{*}{$\mathbf{K}$} & \multicolumn{9}{|c|}{ Químicos } & \multicolumn{4}{|c|}{ Físicos } \\
\hline & & & & P rem & $\mathbf{C a}$ & Mg & $\mathrm{Al}$ & $\mathrm{H}+\mathrm{Al}$ & $\mathbf{T}$ & $\mathbf{m}$ & $\mathbf{V}$ & CMAP $^{(3)}$ & Areia & Silte & Argila & $\mathbf{M O}^{(4)}$ \\
\hline & & \multicolumn{2}{|c|}{$\mathrm{mg} \mathrm{dm}^{-3}$} & $\mathrm{mg} \mathrm{L}^{-1}$ & \multicolumn{5}{|c|}{$\mathrm{cmol}_{\mathrm{c}} \mathrm{dm}^{-3}$} & \multicolumn{2}{|c|}{ ——- } & $\mathrm{mg} \mathrm{kg}^{-1}$ & \multicolumn{4}{|c|}{ dag kg-1 } \\
\hline RQo & 5,2 & 7,5 & 25 & 26,8 & 0,4 & 0,1 & 0,8 & 4,0 & 4,6 & 58 & 12,7 & 306,32 & 92,0 & 2,0 & 6,0 & 1,4 \\
\hline LVA0-1 & 5,2 & 2,0 & 74 & 24,4 & 0,5 & 0,2 & 06 & 4,0 & 4,9 & 40 & 18,4 & 395,49 & 69,0 & 8,0 & 23,0 & 1,9 \\
\hline LVAd-2 & 4,9 & 2,3 & 52 & 17,4 & 0,8 & 0,2 & 0,8 & 6,3 & 7,4 & 41 & 15,3 & 776,08 & 52,0 & 8,0 & 40,0 & 2,6 \\
\hline \multirow[t]{3}{*}{$\mathrm{LVd}$} & 4,7 & 1,4 & 31 & 8,3 & 0,4 & 0,1 & 1,0 & 11,0 & 11,6 & 62 & 5,3 & $1.274,98$ & 25,0 & 6,0 & 69,0 & 4,1 \\
\hline & \multicolumn{16}{|c|}{ Mineralógicos } \\
\hline & $\mathrm{SiO}_{2}$ & & $\mathrm{Al}_{2} \mathrm{O}_{3}$ & $\mathbf{F e}$ & & $\mathrm{TiC}$ & & $\begin{array}{c}\mathbf{P}_{2} \mathbf{O}_{5} \\
-\mathrm{g} \mathrm{kg}^{-1}\end{array}$ & $\mathbf{F e}$ & & $\mathrm{Fe}_{\mathrm{o}}^{(6)}$ & $\mathbf{C} \mathbf{t}^{(7)}$ & $\mathbf{G} \mathbf{b}^{(8)}$ & & $\mathbf{K i}^{(9)}$ & $\mathbf{K} \mathbf{r}^{(10)}$ \\
\hline RQo & 30,6 & & 35,8 & & 0 & 4 , & 7 & 0,0 & & 0 & 0,1 & 778,0 & $\overline{59,0}$ & & 0,85 & 0,65 \\
\hline LVA0-1 & 95,1 & & 97,4 & & 2 & 6 , & & 0,0 & 10 & & 0,1 & 752,0 & 63,0 & & 0,98 & 0,71 \\
\hline LVAd-2 & 137,6 & & 203,9 & & 9 & 11 & & 0,4 & 44 & & 5,8 & 535,6 & 202,3 & & 0,67 & 0,53 \\
\hline LVd & 129,8 & & 319,1 & 171 & & 22 & & 0,9 & 101 & & 9,2 & 292,7 & 358,8 & & 0,41 & 0,26 \\
\hline
\end{tabular}

(1) RQo: Neossolo Quartzarênico órtico textura arenosa, LVAd-1: Latossolo Vermelho-Amarelo distrófico textura média, LVAd2: Latossolo Vermelho-Amarelo distrófico textura argilosa e LVd: Latossolo Vermelho distrófico textura muito argilosa. ${ }^{(2)} \mathrm{pH}$ em água. ${ }^{(3)}$ Capacidade máxima de adsorção de $\mathrm{P} .{ }^{(4)} \mathrm{MO}=\% \mathrm{C}$ x 1,723. ${ }^{(5)}$ Óxidos de Fe livre totais. ${ }^{(6)}$ Óxidos de Fe menos cristalinos. (7) Caulinita. ${ }^{(8)}$ Gibbsita. ${ }^{(9)} \mathrm{Ki}=\mathrm{SiO}_{2} / \mathrm{Al}_{2} \mathrm{O}_{3} \cdot{ }^{(10)} \mathrm{Kr}=\mathrm{SiO}_{2} /\left(\mathrm{Al}_{2} \mathrm{O}_{3}+\mathrm{Fe}_{2} \mathrm{O}_{3}\right)$.

na forma dos reagentes p.a.: $\mathrm{KNO}_{3}, \mathrm{NH}_{4} \mathrm{NO}_{3}$, $\left(\mathrm{NH}_{4}\right)_{2} \mathrm{SO}_{4}, \mathrm{H}_{3} \mathrm{BO}_{3}, \mathrm{CuSO}_{4} .5 \mathrm{H}_{2} \mathrm{O}$ e $\mathrm{ZnSO}_{4} .7 \mathrm{H}_{2} \mathrm{O}$. Foram cultivadas três plantas de braquiarão (Brachiaria brizantha (Hochst. ex A. Rich.) Stapf. cv. Vitória) por vaso, mantendo-se o delineamento experimental anterior (fatorial 4 x 5), porém com três repetições. Aos 90, 160 e 290 dias após a emergência das plântulas, na fase de pré-florescimento, foram efetuados cortes a $4 \mathrm{~cm}$ da superfície do solo Após o primeiro e o segundo corte foram realizadas adubações em cobertura, totalizando 240,170 e $60 \mathrm{mg} \mathrm{dm}^{-3} \mathrm{de}$ $\mathrm{N}, \mathrm{K}$ e S, respectivamente. Durante o período experimental, a umidade dos solos foi mantida a $60 \%$ do volume total de poros, usando-se água deionizada. A parte aérea das plantas foi seca em estufa com circulação forçada de ar a $65-70{ }^{\circ} \mathrm{C}$ por $72 \mathrm{~h}$, pesada, moída e analisada quanto a P (Malavolta et al., 1997). Os dados foram submetidos à análise de variância e a estudos de regressão simples, ajustando-se modelos em função dos tratamentos aplicados, utilizando o programa de análises estatísticas SISVAR (Ferreira, 2000).

\section{RESULTADOS E DISCUSSÃO}

As doses de calcário e de esterco de curral e a interação entre ambas influenciaram significativamente a produção de matéria seca da parte aérea (MSPA) e o acúmulo total de $\mathrm{P}$ na parte aérea do braquiarão. O aumento das doses de esterco promoveu incremento na produção da forrageira em todas as doses de calcário e em todos os solos, à exceção das doses 1 e 2 no solo RQo e da dose 2 no LVd (Figura 1).
Na maioria dos casos, equações lineares foram as que melhor se ajustaram aos dados, indicando que as doses de esterco foram insuficientes para a produção máxima. As maiores respostas à aplicação de esterco foram observadas nas doses de 0 e 0,5 de calcário; na dose 2, o efeito da aplicação de esterco foi insignificante. Em todos os solos, o braquiarão respondeu à aplicação das doses de calcário; as maiores respostas ocorreram nas menores doses de esterco. Observou-se que o efeito de cada fator foi mais evidente na ausência do outro, pois a aplicação de resíduos orgânicos e calagem apresenta efeitos semelhantes na correção da acidez e neutralização de toxidez por $\mathrm{Al}$ no solo, como observado por outros autores (Miyazawa et al., 1993; Franchini et al., 1999; Sumner \& Pavan, 2000).

A produção do braquiarão foi diretamente proporcional à do $\mathrm{P}$ remanescente (P-rem) e inversamente proporcional à capacidade máxima de adsorção de $\mathrm{P}$ (CMAP), que representam a capacidade do solo em repor o P em solução (Quadro 1 e Figura 1). Esse incremento na produção pode ser creditado, também, ao aumento nos teores de $\mathrm{P}$ disponível no solo, pois a elevação dos teores de MO e correção do $\mathrm{pH}$, alterando os atributos ligados ao fator capacidade de $\mathrm{P}$ dos solos (redução da CMAP e aumento do Prem), aumenta a disponibilidade do nutriente (Souza et al., 2006), favorecendo sua maior absorção e incrementando a produção.

Com o aumento das doses de esterco, pode ter ocorrido bloqueio dos sítios de adsorção de $\mathrm{P}$ no solo, pela ligação dos grupos funcionais carboxílicos e fenólicos da $\mathrm{MO}$ às hidroxilas dos óxidos de $\mathrm{Fe}$ e $\mathrm{Al}$ e complexação do Al em solução (Hue, 1991). Segundo Haynes (1984), o solo pode adsorver ácidos orgânicos 
Produção de MS
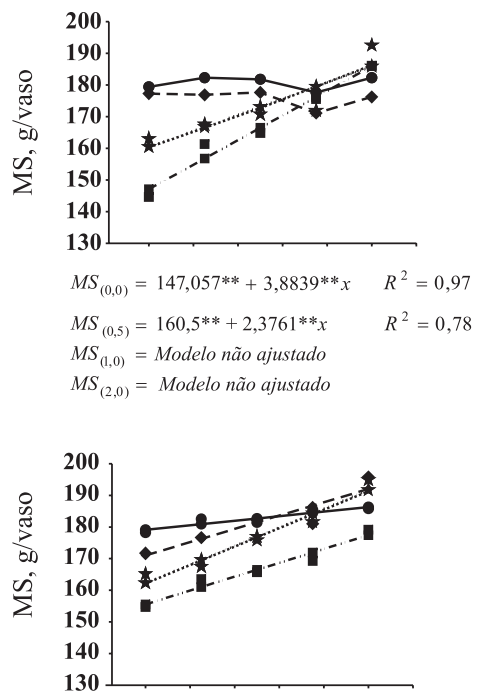

$M S_{(0,0)}=155,54^{* *}+2,18867 * * x \quad R^{2}=0,94$ $M S_{(0,5)}=162,3173 * *+2,9436 * * x R^{2}=0,94$ $M S_{(1,0)}=170,9993 * *+2,101^{* *} x \quad R^{2}=0,85$ $M S_{(2,0)}=179,096 * *+0,721^{* * x} \quad R^{2}=0,84$

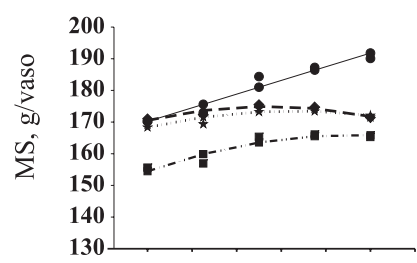

$M S_{(0,0)}=154,46 * *+2,49 * x-0,135 * * x^{2} \quad R^{2}=0,87$ $M S_{(0,5)}=168,34 * *+1,5715^{*} * x-0,1194 * * x^{2} \quad R^{2}=0,69$ $M S_{(1,0)}=170,5 * *+1,6354 * * x-0,15 * * x^{2} \quad R^{2}=0,84$ $M S_{(2,0)}=170,2187 * *+2,15347 * *_{x} \quad R^{2}=0,93$

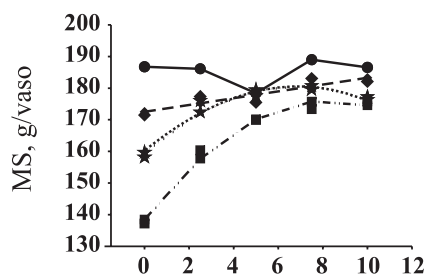
ESTERCO BOVINO, \%

$M S_{(0,0)}=138,46 * *+9,064 * * x-0,5454 * * x^{2} R^{2}=0,98$ $M S_{(0,5)}=159,69 * *+6,237 * * x-0,457 * * x^{2} \quad R^{2}=0,93$ $M S_{(1,0)}=172523 * *+10757^{* * x} \quad R^{2}=0,79$ $M S_{(2,0)}=$ Modelo não ajustado

$R^{2}=0,79$

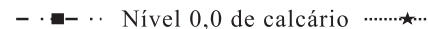
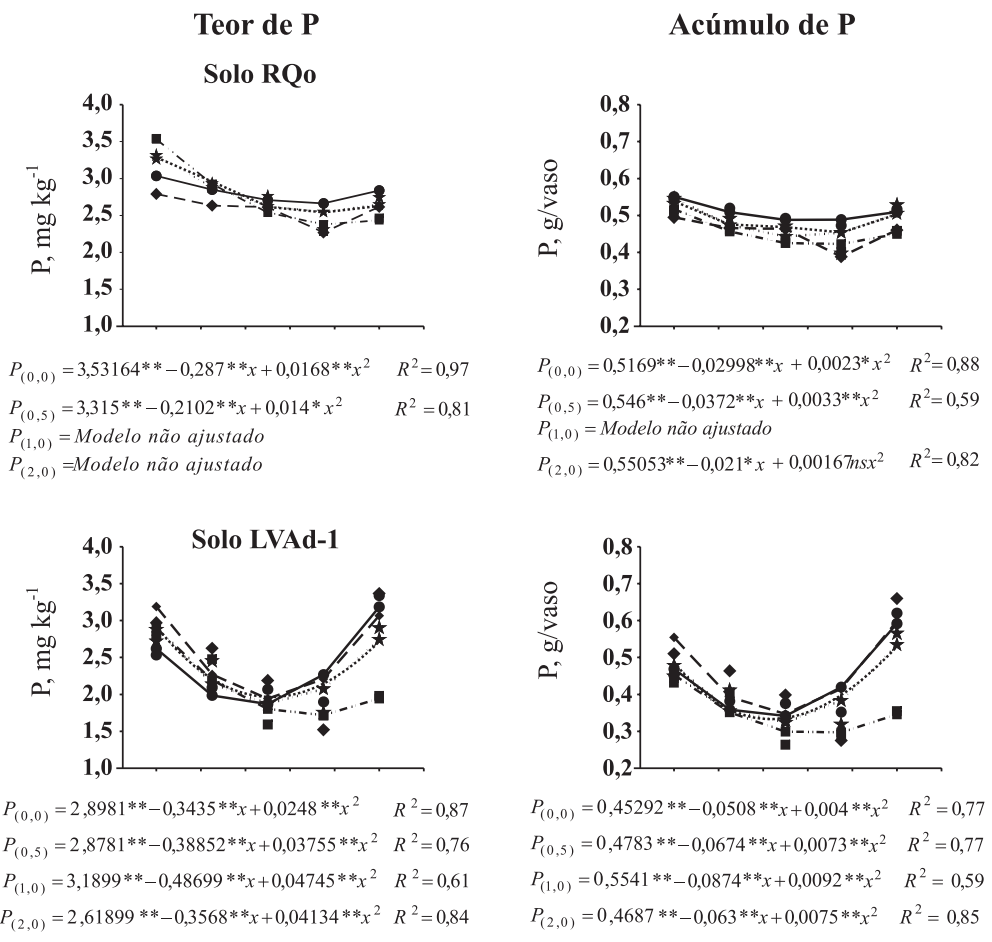

$P_{(0,0)}=0,45292 * *-0,0508 * * x+0,004 * * x^{2} \quad R^{2}=0,77$ $P_{(0,5)}=0,4783 * *-0,0674 * * x+0,0073 * * x^{2} \quad R^{2}=0,77$ $P_{(1,0)}=0,5541 * *-0,0874 * * x+0,0092 * * x^{2} \quad R^{2}=0,59$ $P_{(2,0)}=0,4687 * *-0,063 * * x+0,0075 * * x^{2} \quad R^{2}=0,85$
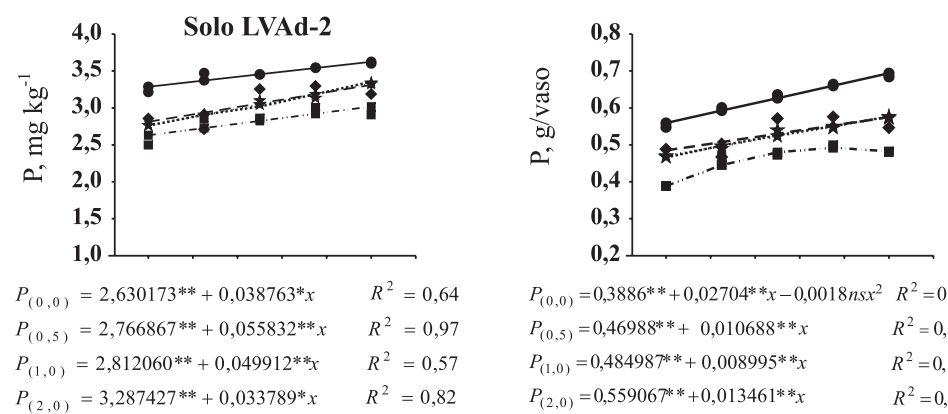

$P_{(0,0)}=0,3886 * *+0,02704 * * x-0,0018 n s x^{2} \quad R^{2}=0,99$ $P_{(0,5)}=0,46988^{* *}+0,010688^{* *} x \quad R^{2}=0,95$ $P_{(1,0)}=0,484987^{* *}+0,008995^{* *} x \quad R^{2}=0,52$ $P_{(2,0)}=0,559067^{* *}+0,013461^{* *} x \quad R^{2}=0,97$

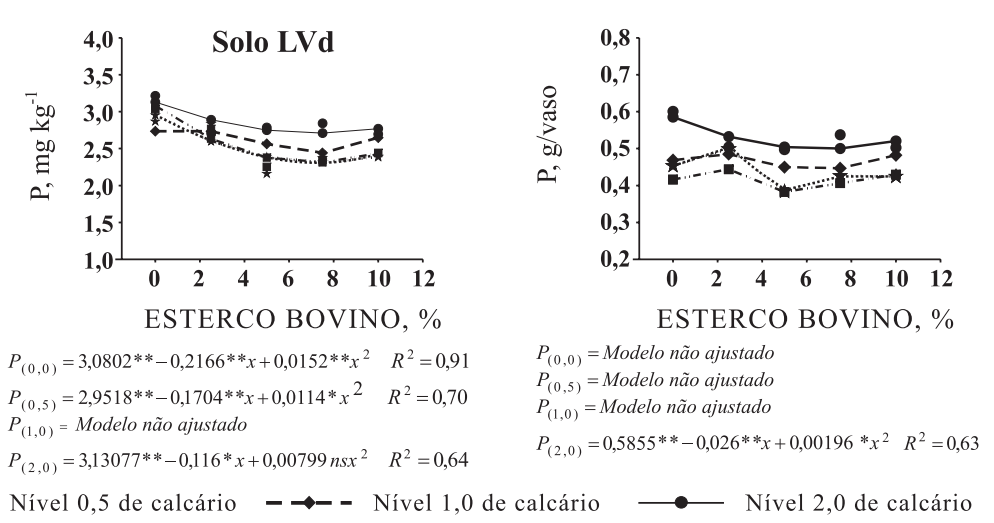

Figura 1. Produção de matéria seca (MS), teores e acúmulo de fósforo na MS da parte aérea do braquiarão, em função das doses de esterco bovino, em quatro doses de calagem.

com grande energia, competindo com sítios de adsorção de $\mathrm{P}$ e aumentando a disponibilidade desse nutriente às plantas. A MO pode originar, também, ligantes orgânicos liberados durante o processo de mineralização, que podem formar complexos com o $\mathrm{Al}$ ou complexos solúveis com o P da solução do solo, evitando que ele seja adsorvido (Iyamuremye et al., 1996). Todavia, com as doses maiores de esterco pode ocorrer redução na disponibilidade de $\mathrm{P}$ devido à sua adsorção aos compostos húmicos, dado o caráter aniônico da MO, que, por meio de pontes de cátions (Al, Fe e Ca), retém o nutriente (Novais \& Smyth, 1999). 
Os incrementos na produção devidos à calagem, principalmente nas doses mais baixas de esterco (Figura 1), podem ser creditados à redução da toxidez por $\mathrm{Al}$ e, ou, Fe em solução ou a seu efeito na dinâmica do processo de precipitação de fosfatos no solo. Entretanto, a retenção de P pelo solo mantém-se em valores estequiométricos semelhantes quando se substitui a precipitação do $\mathrm{P}$ pelo $\mathrm{Al}^{3+}$ do solo ácido pela sua adsorção pelo hidróxido de $\mathrm{Al}$ recém-formado pela calagem (Haynes, 1984). A elevação do pH promove também a desprotonação de hidroxilas de radicais orgânicos e daquelas expostas na superfície das argilas, aumentando a repulsão entre o fosfato e a superfície adsorvente (Novais \& Smyth, 1999).

Interações matéria orgânica $\mathrm{x}$ calagem têm sido observadas em muitas pesquisas, como nas de Miranda (1983), Quaggio et al. (1985) e Faquin et al. (1998). No cultivo de diversas culturas, essas pesquisas demonstraram que, em solos ácidos com elevados teores de MO, a calagem deve ser feita para elevar o pH em água a 5,0 - 5,2 e a saturação por bases a cerca de $50 \%$, valores abaixo daqueles normalmente recomendados para solos minerais. Esse efeito devese à presença de compostos orgânicos, que, complexando o $\mathrm{Al}$, reduzem não só a toxidez do elemento sobre as plantas, mas também ocupam os sítios de adsorção, aumentando a disponibilidade de fosfato.

As maiores produções observadas com o aumento nas doses de esterco, na ausência de calcário, e nas maiores doses de calagem, na ausência de esterco (Figura 1), podem ser devidas, também, a outros efeitos e não somente ao aumento da disponibilidade de $\mathrm{P}$, como a neutralização do $\mathrm{Al}$ e do Mn tóxicos em solos ácidos.

O aumento nas doses de esterco promoveu, inicialmente, redução nos teores e no acúmulo de $\mathrm{P}$ na matéria seca do braquiarão em todas as doses de calcário e em todos os solos estudados, exceto no LVAd-2, devido, provavelmente, a efeitos de diluição (Figura 1). Contudo, houve tendência de elevação nos teores e quantidades acumuladas de $\mathrm{P}$ com a aplicação das doses mais elevadas de esterco. As doses de calcário também aumentaram o acúmulo de $\mathrm{P}$, sendo esse efeito mais evidente nos solos LVAd-2 e LVd, mais argilosos e goethíticos, retendo mais fortemente o $\mathrm{P}$ adicionado. $\mathrm{O}$ processo de adsorção de $\mathrm{P}$ pelos óxidos, hidróxidos e oxi-hidróxidos de $\mathrm{Fe}$ e Al é um dos principais fatores envolvidos na imobilização desse nutriente em solos tropicais (Lopes \& Cox, 1979). A goethita é considerada a principal responsável pelo fenômeno de adsorção de P nos solos do Brasil Central (Bahia Filho et al., 1983). Essa maior capacidade de adsorção de $\mathrm{P}$ nos solos goethíticos foi também constatada por Curi \& Franzmeier (1984), sendo creditada à facilidade de acesso do fosfato aos grupos $\mathrm{OH}^{-}$de superfície (Frossard et al., 1994). Ocorrem também reações de adsorção de fosfato por caulinita e gibbsita, que apresentam grupos $\mathrm{OH}$ expostos e alta afinidade pelo P (Mcbride, 1994). De acordo com esse autor, em condições de solo ácido, o íon fosfato reage rapidamente com o octaedro de $\mathrm{Al}$, pela substituição dos grupos $\mathrm{OH}$ localizados na superfície do mineral, formando complexos de esfera interna. São observadas também reações de precipitação do $\mathrm{P}$ com formas iônicas de $\mathrm{Al}$ e $\mathrm{Fe}$, em solos ácidos, e $\mathrm{Ca}$, em meio básico, formando compostos de baixa solubilidade (Novais \& Smyth, 1999).

O acúmulo total de $\mathrm{P}$ na parte aérea do braquiarão foi inversamente proporcional ao da CMAP e diretamente proporcional ao de P-rem e P Mehlich-1 (Quadro 1 e Figura 1). Apesar dos menores valores de P-rem e maiores valores de CMAP dos solos mais argilosos, não se verificaram diferenças pronunciadas no acúmulo de $\mathrm{P}$ pelo braquiarão cultivado nos diferentes solos. Isso ocorreu, possivelmente, devido à maior capacidade de armazenamento de $\mathrm{P}$ dos solos argilosos (Novais \& Smyth, 1999). Segundo esses autores, a maior ou menor competição entre plantas e solo pelo $\mathrm{P}$ aplicado faz com que a planta se ajuste para utilizar o $\mathrm{P}$ que lhe é colocado à disposição. A CMAP e o P-rem são atributos que refletem o podertampão ou fator capacidade de P no solo. Dessa forma, quando o $\mathrm{P}$ é o único fator limitante à produção, além das variações entre espécies ou cultivares, idade do tecido vegetal, forma do nutriente, interação entre nutrientes e condições ambientais, a CMAP deve ser considerada na interpretação dos conteúdos de P nas plantas (Muniz et al., 1985). A variação na adsorção de $\mathrm{P}$ entre os solos normalmente está associada à mineralogia, à textura e aos teores de MO do solo (Bahia Filho et al., 1983; Muniz et al., 1985). Vários autores observaram relação inversa entre o $\mathrm{P}$ absorvido pela planta e o fator capacidade de $\mathrm{P}$ do solo (Holford \& Mattingly, 1976; Bahia Filho et al., 1983; Muniz et al., 1985; Fabres et al., 1987; Fernandes et al., 1998). No entanto, o maior conteúdo da fração de $\mathrm{P}$ pouco lábil apresentado pelos solos mais argilosos supre o P em solução, contrabalançando as diferenças de $\mathrm{P}$ disponível apresentadas pelos diferentes solos.

\section{CONCLUSÕES}

1. A calagem e a adubação orgânica influenciaram de forma positiva o efeito residual da adubação fosfatada, aplicada ao feijoeiro, sobre a nutrição fosfatada do braquiarão cultivado em sucessão.

2. Para todos os solos estudados, as aplicações de esterco de curral e de calcário na cultura do feijoeiro promoveram incrementos significativos na produção do braquiarão.

\section{LITERATURA CITADA}

ALVAREZ V., V.H. \& FONSECA, D.B. Definição de doses de fósforo para determinação da capacidade máxima de adsorção de fosfatos e para ensaios em casa de vegetação. R. Bras. Ci. Solo, 14:49-55, 1990. 
ALVAREZ V., V.H.; NOVAIS, R.F.; DIAS, L.E. \& OLIVEIRA, J.A. Determinação e uso do fósforo remanescente. B. Inf. SBCS, 25:27-32, 2000.

BAHIA FILHO, A.F.C.; BRAGA, J.M.; RESENDE, M. \& RIBEIRO, A.C. Relação entre adsorção de fósforo e componentes mineralógicos da fração argila de Latossolos do Planalto Central. R. Bras. Ci. Solo, 7:221-226, 1983.

CURI, N. \& FRANZMEIER, D.P. Toposequence of Oxisols from the Central Plateau of Brazil. Soil Sci. Soc. Am. J., 48:341-346, 1984.

DAY, P.R. Particle fractionation and particle-size analysis. In: BLACK, C.A., ed. Methods of soil analysis. Madison, America Society of Agronomy, 1965. v.1. p.545-566.

EMPRESA BRASILEIRA DE PESQUISA AGROPECUÁRIA EMBRAPA. Centro Nacional de Pesquisa de Solos. Sistema brasileiro de classificação de solos. Rio de Janeiro, 1999. $412 p$

EMPRESA BRASILEIRA DE PESQUISA AGROPECUÁRIA EMBRAPA. Serviço Nacional de Levantamento e Conservação do Solo. Manual de métodos de análise do solo. Rio de Janeiro, Ministério da Agricultura, 1997. 212p.

FABRES, A.S.; NOVAIS, R.F.; NEVES, J.C.L.; BARROS, N.F. \& CORDEIRO, A.T. Níveis críticos de diferentes frações de fósforo em plantas de alface cultivado em diferentes solos. R. Bras. Ci. Solo, 11:51-57, 1987.

FAQUIN, V.; ANDRADE, C.A.B.; FURTINI NETO, A.E.; ANDRADE, A.T. \& CURI, N. Resposta do feijoeiro à aplicação de calcário em solos de várzea do sul de Minas Gerais. R. Bras. Ci. Solo, 22:651-660, 1998.

FERNANDES, L.A.; FURTINE NETO, A.E.; CURI, N.; GUEDES, G.A.A. \& LIMA, J.M. Fósforo e atividade da fosfatase ácida em plantas de feijoeiro. Pesq. Agropec. Bras., 35:769-778, 1998.

FERREIRA, D.F. Análises estatísticas por meio do SISVAR (Sistema para Análise de Variância) para Windows versão 4.0. In: REUNIÃO ANUAL DA REGIÃO BRASILEIRA DA SOCIEDADE INTERNACIONAL DE BIOMETRIA, 45., São Carlos, 2000. Anais. São Carlos, Universidade Federal de São Carlos, 2000. p.255-258.

FRANCHINI, J.C.; MALAVOLTA, E.; MIYAZAWA, M. \& PAVAN, M.A. Alterações químicas em solos ácidos após a aplicação de resíduos vegetais. R. Bras. Ci. Solo, 23:533$542,1999$.

FROSSARD, E.; BROSSARD, M.; HEDLEY, M.J. \& METHERELL, A. Reactions controlling the cycling of $\mathrm{P}$ in soils. In: TIESSEN, H., ed. P cycling in terrestrial and aquatic ecosystem: a global perspective. New York, John Wiley \& Sons, 1994. p.1-65.

HAYNES, R.J. Lime and phosphate in the soil-plant system. Adv. Agron., 37:249-315, 1984.

HOLFORD, I.C.R. \& MATTINGLY, G.E.G. Phosphate adsorption and availability plant of phosphate. Plant Soil, 44:377-389, 1976.
HUE, N.V. Effects of organics acids/anions on P sorption and phytvailability in soils with different mineralogies. Soil Sci., 152:463-471, 1991.

IYAMUREMYE, F.; DICK, R.P. \& BAHAM, J. Organic amendments and phosphorus dynamics: Phosphorus chemistry and sorption. Soil Sci., 161:426-435, 1996.

KLUG, H.P. \& ALEXANDER, L.E. X-ray diffraction procedures for polycrystalline and amorphous materials. New York, John Wiley, 1974. 716p.

KLUTHCOUSKI, J.; STONE, L.F.; AIDAR, H. \& COBUCCI, T. Integração lavoura-pecuária e o manejo de plantas daninhas. Inf. Agron., 106:1-20, 2004.

KRISHNA MURTI, G.S.R.; VOLK, V.V. \& JACKSON, M.L. Calorimetric determination of iron of mixed valency by Orthophenantroline. Soil Sci. Soc. Am. Proc., 30:663-664, 1966.

LOPES, A.S. \& COX, F.R. Relação de características físicas, químicas e mineralógicas com fixação de fósforo em solos sob Cerrados. R. Bras. Ci. Solo, 3:82-88, 1979.

MALAVOLTA, E.; VITTI, G.C. \& OLIVEIRA, S.A. Avaliação do estado nutricional das plantas - princípios e aplicações. Piracicaba, Potafos, 1997. 210p.

McBRIDE, M.B. Enviromental chemitry of soils. New York, University Press, 1994. 406p.

MEHRA, O.P. \& JACKSON, N.L. Iron oxide removal from soils and clays by a dithionite-citrate system buffered with sodium bicarbonate. Clays Clays Miner., 3:317-327, 1960.

MIELNICZUK, J.; BAYER, C.; VEZZANI, F.M.; LOVATO, T.; FERNANDES, F.F. \& DEBARBA, L. Manejo de solo e culturas e sua relação com os estoques de carbono e nitrogênio do solo. In: CURI, N.; MARQUES, J.J.; GUILHERME, L.R.G.; LIMA, J.M.; LOPES, A.S. \& ALVAREZ V., V.H. Tópicos em ciência do solo. Viçosa, MG, Sociedade Brasileira de Ciência do Solo, 2003. v.3. p.209-248.

MIRANDA, L.N. Resposta da sucessão soja-trigo a doses e modo de aplicação de calcário em solo glei pouco húmico. R. Bras. Ci. Solo, 17:75-82, 1983.

MIYAZAWA, M.; PAVAN, M.A. \& CALEGARI, A. Efeito de material vegetal na acidez do solo. R. Bras. Ci. Solo, 17:411416, 1993.

MUNIZ, A.S.; NOVAIS, R.F.; BARROS, N.F. \& NEVES, J.C.L. Nível crítico de fósforo na parte aérea da soja como variável do fator capacidade de fósforo. R. Bras. Ci. Solo, 9:237-244, 1985.

NOVAIS, R.F. \& SMYTH, T.J. Fósforo em solo e planta em condições tropicais. Viçosa, MG, Universidade Federal de Viçosa, 1999. 399p.

QUAGGIO, J.A.; SAKAI, M.; ISHIMURA, I.; SAES, L.A. \& BATAGLIA, O.C. Calagem para a rotação feijão-milho verde em solo orgânico do vale do Rio Ribeira de Iguape (SP). R. Bras. Ci. Solo, 9:256-262, 1985. 
RAIJ, B.van. Fertilidade do solo e adubação. Piracicaba, Ceres/ Potafos, 1991. 343p.

RAIJ, B.van; CANTARELLA, H.; QUAGGIO, J.A.; FERREIRA, H.E.; LOPES, A.S. \& BATAGLIA, O.C. Análise química do solo para fins de fertilidade. Campinas, Fundação Cargil, 1987. 170p.

SANCHEZ, P.A. \& LOGAN, T.J. Myths and science about the chemistry and fertility of soils In the tropics. In: LAL, R. \& SANCHEZ, P.A., eds. Myths and science of the tropics. Madison, Soil Science Society of America, 1992. p.35-46.

SANCHEZ, P. \& SALINAS, J.G. Low-input tecnology for managins Oxisols and Ultisols in tropical America. Adv. Agron., 34:278-406, 1981.
SANO, E.E.; BARCELLOS, A.O. \& BESERRA, H.S. Assessing the spatial distribution of cultivated pastures in the Brazilian savanna. Past. Trop., 22:2-15, 2000.

SCHWERTMANN, U. Differenzierung der eisenoxide des bondes durch extraktion mit ammonium-oxalat-losung. Zeitschrift fuer Pflanzernahrung, 105:194-202, 1964.

SOUZA, R.F.; FAQUIN, V.F.; TORRES, P.R.F. \& BALIZA, D.P. Calagem e adubação orgânica: Influência na adsorção de fósforo em solos. R. Bras. Ci. Solo, 30:975-983, 2006.

SUMNER, M.E. \& PAVAN, M.A. Alleviating soil acidity through organic matter management. In: ROTAÇÃO SOJA/ MILHO NO PLANTIO DIRETO, 2000, Piracicaba. Anais. Piracicaba, Potafos, 2000. CD-ROM. 